\title{
Pressure ulcer treatment in a long-term care setting: wound bed healing with clostridial collagenase ointment versus hydrogel dressing
}

This article was published in the following Dove Press journal:

Chronic Wound Care Management and Research

30 October 2014

Number of times this article has been viewed

\author{
Curtis R Waycaster ${ }^{1,2}$ \\ Adrienne M Gilligan ${ }^{1,2}$ \\ Catherine T Milne ${ }^{3}$ \\ 'Smith and Nephew Inc., Fort \\ Worth, TX, USA; ${ }^{2}$ Department of \\ Pharmacotherapy, University of North \\ Texas Health Sciences Center, Fort \\ Worth, TX, USA; ${ }^{3}$ Connecticut Clinical \\ Nursing Associates LLC, Bristol, CT, \\ USA
}

Purpose: To compare clinical outcomes in patients with pressure ulcers (PUs) who were treated with enzymatic debridement using clostridial collagenase ointment (CCO) with those treated with autolytic debridement using a hydrogel dressing.

Patients and methods: This prospective, randomized, blinded, single-site trial directly compared the use of $\mathrm{CCO}$ and hydrogel dressings for treatment of PUs in patients in a long-term care facility. Changes in wound bed scores (WBS), tissue granulation, wound surface area, and epithelialization were assessed weekly during the 6-week treatment. Effects of treatment time, treatment method, and the combination of treatment time and method on continuous outcomes were analyzed by linear regression; the effects of covariates on epithelialization were analyzed by logistic regression.

Results: Overall, 27 patients completed the study; 13 patients were treated with CCO and 14 with hydrogel. Baseline demographic and clinical characteristics were similar between the treatment groups. Patients treated with $\mathrm{CCO}$ had a granulation rate approximately twice that of those receiving hydrogel and showed a significantly higher rate of granulation tissue formation at week 6 . Treatment duration and the combination of treatment duration and method were significant predictors of granulation tissue formation. WBS improvements from baseline to week 6 were greater in patients who received $\mathrm{CCO}$ than in those treated with hydrogel ( +4.6 units versus +2.6 units, respectively). Treatment duration and the combination of treatment duration and method were predictors of WBS improvement. Patients treated with CCO showed significant reductions in wound surface area from baseline $\left(10.3 \mathrm{~cm}^{2}\right)$ to week $6\left(2.1 \mathrm{~cm}^{2}\right)$. At week 6 , epithelialization was numerically higher in patients treated with CCO than in patients treated with hydrogel.

Conclusion: Long-term care facility patients with PUs who received enzymatic debridement with $\mathrm{CCO}$ had greater improvements in granulation tissue formation, WBS, wound surface area, and wound closure than did those treated with hydrogel.

Keywords: debridement, wound surface area, wound bed score, epithelialization, hydrogel dressing, collagenase ointment

\section{Introduction}

Pressure ulcer (PU) treatment poses substantial economic and clinical challenges to health care systems. In the US, PU prevalence in long-term care facilities ranges from $2.2 \%$ to $23.9 \%,{ }^{1}$ and expenditures for treating PUs have been estimated at $\$ 11$ billion per year. ${ }^{2,3}$ Clinically, the development of PUs can interfere with functional recovery, may be complicated by pain and infection, and can contribute to excesses in hospital length of stay. ${ }^{4}$ PUs are markers of poor overall health and may contribute to premature mortality in some patients. ${ }^{5,6}$
Correspondence: Curtis R Waycaster Smith and Nephew Inc., 3909 Hulen Street, Fort Worth, TX 76107, USA $\mathrm{Tel}+\mathrm{I} 8179004035$

Fax + I 817900 4085

Email curtis.waycaster@smith-nephew.com 
An essential component of treating chronic wounds such as PUs is wound bed preparation (WBP). ${ }^{7}$ WBP consists of controlling exudate and edema, removing necrotic tissue, decreasing the bacterial burden, and promoting healthy granulation tissue. ${ }^{8-10}$ Debridement, a key step of WBP, in which barriers to healing are cleared from the wound, ${ }^{11}$ may be performed using autolytic, biologic, enzymatic, surgical, and mechanical techniques. ${ }^{12}$ The recommended debridement approach depends on wound type, likelihood of infection, patient characteristics, treatment time, available medical expertise, and care setting resources..$^{13,14}$

Within long-term care facilities, autolytic and enzymatic debridement methods have long been accepted as effective strategies for wound management, because both methods are considered safe, practical, and simple. ${ }^{15}$ Compared with mechanical debridement alone using wet-to-dry dressings and high-pressure irrigation or pulsed lavage and hydrotherapy, enzymatic and autolytic debridement methods are more efficacious, ${ }^{16-18}$ less painful for the patient, ${ }^{19}$ and more cost-effective. ${ }^{20}$ Mechanical debridement using only wetto-dry dressings and/or hydrotherapy may be justified in the early stages of acute wound treatment; however, it can be detrimental to friable granulation tissue. ${ }^{7,21}$ Biologic (larval) debridement has been known to accelerate the wound healing process, assist with wound odor, and substantially decrease bacterial count; ${ }^{22-25}$ however, resistance of use from both US health care providers and patients has been reported..$^{26}$ Both enzymatic and autolytic methods have an advantage over sharp debridement because they do not require a licensed provider (eg, physician, surgeon, nurse practitioner) whose education, training, and scope of practice require their physical presence to accomplish the task. This may reduce treatment initiation times and potentially reduce cost. ${ }^{19,27,28}$

Autolytic debridement using a hydrogel that is composed of hydrophilic polymers in a dimensional matrix can be accomplished by placing an occlusive dressing on a wound. ${ }^{11}$ This generates a moist wound environment that facilitates liquefaction of necrotic tissue, which can then be removed by washing the wound and changing the dressing. ${ }^{12,17,29}$ Benefits of autolytic debridement include ease of use, little/no pain, and no damage to healthy tissue. ${ }^{30}$ However, excessive use or use in a highly exudative wound may lead to maceration of the periwound skin, which may impede the wound healing process. ${ }^{30}$

Enzymatic debridement is an active and selective method of wound debridement that uses naturally occurring proteolytic enzymes for eliminating barriers to the healing process. ${ }^{31}$ Enzymatic debridement with clostridial collagenase ointment (CCO) (derived from Clostridium histolyticum) has been shown to be sparing to collagen in healthy tissue and newly formed granulation tissue. ${ }^{32} \mathrm{CCO}$ has been used for the removal of necrotic tissue from chronic cutaneous wounds and burns; however, $\mathrm{CCO}$ activity may be adversely impacted when used with products that contain heavy metals such as silver. ${ }^{12}$ Clinical advantages of enzymatic debridement with CCO that contribute to granulation tissue formation and subsequent epithelialization include selective removal of necrotic debris, painless application, minimal blood loss, and enhanced tissue proliferation. Patients may experience temporary redness, especially if $\mathrm{CCO}$ comes into contact with skin around the wound. ${ }^{12}$

Effective debridement has been associated with more rapid and an increased probability of wound healing. ${ }^{15,33}$ However, few studies have compared the effectiveness of enzymatic with autolytic debridement based upon wound healing parameters in the long-term care setting. To address this need, this study compares outcomes of PUs treated in a long-term care setting with enzymatic debridement using $\mathrm{CCO}$ with outcomes of PUs treated with autolytic debridement using a hydrogel. Relative changes in granulation tissue formation, wound surface area, wound bed scores (WBS), and epithelialization were assessed.

\section{Patients and Methods}

This US-based, prospective, randomized clinical trial was conducted in a single long-term care facility. The study consisted of a 6-week initial phase followed by a 6-week extension phase. Due to a loss to follow-up in Phase II, only results of Phase I (ie, the initial phase) are reported here. The results from the Phase II study can be found elsewhere in the literature. ${ }^{33}$ Inclusion and exclusion criteria are presented in Table 1. Mean time between discovery of the PU and enrolment into the study ranged from 3.0 to 3.7 weeks. There was no statistical difference between the two groups. Wounds were staged based upon recommended guidelines from the National Pressure Ulcer Advisory Panel and the European Pressure Ulcer Advisory Panel. ${ }^{34}$ The local Institutional Review Boards of the long-term care facilities from which patients were recruited approved the study protocol. Written informed consent was provided by each patient or legal representative. Randomization occurred using a random number generator after informed consent was obtained, to reduce selection bias.

Study design details have been reported previously. ${ }^{15,33}$ Briefly, patients were randomly assigned to receive daily dressing changes with either CCO (Santyl ${ }^{\circledR}$ Ointment, Smith and Nephew Inc. [formerly Healthpoint Biotherapeutics], Fort Worth, TX, USA) or a hydrogel (SoloSite ${ }^{\mathrm{TM}}$ Gel, Smith and 
Table I Inclusion and exclusion criteria

\begin{tabular}{l} 
Inclusion criteria \\
Age $>18$ years \\
Presence of $\geq 85 \%$ necrotic tissue on a pressure ulcer between $I \mathrm{~cm}^{2}$ \\
and $64 \mathrm{~cm}^{2}$ \\
No current use of parenteral or oral antibiotics, except urinary tract \\
suppressive therapy \\
Hemoglobin $A_{\text {Ic }}<7.9 \%$ \\
Currently receiving adequate pressure redistribution to the affected \\
area via devices such as a group 2 or group 3 specialty bed and a static \\
air wheelchair cushion (if out of bed) and/or an offloading device if the \\
pressure ulcer was located on the lower extremity \\
Study pressure ulcer naïve to hydrogel or collagenase dressing \\
No allergies to hydrogel or collagenase \\
No allergies to semiocclusive secondary dressing \\
Compliance with nutritional interventions per registered dietician \\
Written informed consent \\
Exclusion criteria \\
Steroid use $>5$ mg daily \\
Inability to cooperate with offloading recommendations \\
Ankle brachial index $<0.85$ if study pressure ulcer on a lower extremity \\
Presence of callus requiring sharp or surgical debridement within 3 days \\
prior to treatment \\
Pregnancy \\
Medical instability as deemed by the investigator \\
Participation in another clinical trial or wound dressing evaluation \\
30 days prior to enrolment \\
\hline
\end{tabular}

Note: Reproduced with permission from Milne CT, Ciccarelli AO, Lassy M. A comparison of collagenase to hydrogel dressings in wound debridement. Wounds. 2010;22(II):270-274..$^{15}$

Nephew Inc., St Petersburg, FL, USA) covered with a standard semiocclusive dressing. To replicate common clinical practice in long-term care facilities, the recommended procedure for CCO application (cross-hatching), ${ }^{35}$ which consists of scoring of nonviable tissue using a No 10 blade to expose more surface area for treatment exposure, was not performed in either treatment arm. Since serial sharp debridement and cross-hatching were not performed, blood loss in the two treatment arms was not assessed. Application of each treatment was performed by the same nurses (two for each shift) in the facility, who were trained by the investigator to do daily applications. The investigator performed the treatment weekly while performing patient and wound assessments. Following the application of the treatment agents, the wound was filled to the depth equal to that of the surrounding wound tissue with gauze dampened with normal saline so there was no excess moisture. This area was then covered with a semiocclusive dressing (COVRSITE ${ }^{\circledR}$, Smith and Nephew, Largo, FL, USA). The nursing staff performed dressing changes daily unless the dressing integrity was lost and more frequent dressing changes were necessary. Soiling with fecal or urinary incontinence or inadvertent removal of the dressing as to expose the wound was defined as loss of dressing integrity. Dressing changes consisted of normal saline irrigation followed by application of the assigned treatment agent (nickel thick) to the entire wound bed. The wound was then covered with a semiocclusive dressing.

During initial assessment and prior to the application of treatment, wounds were irrigated with normal saline using a device that delivered 4-15 pound-force per square inch (IrriMax ${ }^{\circledR}$, IrriMax Corporation, Weston, FL, USA), and wound photographs were taken at baseline and weekly thereafter. In addition, wounds could not have been previously treated with either hydrogel or collagenase. Weekly subject evaluations, conducted by the same investigator, included subject assessment, wound assessment (including risk of infection), and wound photographs. The protocol was not modified between weekly assessments (ie, no adjustments were made to the treatment regimen between assessments). Clinical outcomes of interest included changes in wound surface area, WBS, granulation tissue formation, and epithelialization. Wound images were assessed by two blinded primary study investigators using calibrated, noninvasive wound measurement planimetry software (PictZar ${ }^{\circledR}$, Biovisual Technologies, Elmwood Park, NJ, USA). Digital planimetry results in more accurate wound measurements compared with standard manual measurements (length $\times$ width), which may overestimate wound area by as much as $40 \%{ }^{36}$ The investigators followed the manufacturer's recommendations for obtaining planimetry. ${ }^{37}$ Each wound photograph was scored using the Pressure Ulcer Scale for Healing (PUSH) tool (Version 3.04) and the WBS assessment. Both of these tools have been tested for clinical validity and reliability to track wound healing status over time. PUSH scores range from 0 to 17 , with lower scores signifying wound improvement. ${ }^{38}$ The WBS has a range of $0-16$, with higher scores indicating improvement. ${ }^{39}$

Differences in demographic and clinical characteristics at baseline were analyzed with one-way analysis of variance for continuous covariates and chi-square analysis for dichotomous variables of interest. Effects of time, treatment, and an interaction of time and treatment on continuous outcomes were assessed with linear regression analyses. A goodness of fit test was performed to validate that outcomes were linear. ${ }^{40}$ The effects of covariates on epithelialization were analyzed using logistic regression. Treatment effect was calculated using Cohen's $d$ statistic for WBS, wound surface area, and granulation tissue formation.

\section{Results}

During the 1-year enrolment period, 42 patients were approached to participate in the trial and 27 subjects 
consented to participate. Of 27 enrolled patients, 13 patients were randomized to receive $\mathrm{CCO}$ and 14 randomized to hydrogel. Phase I completion, defined as 6 weeks of treatment for full debridement (whichever came first), was attained by all enrolled patients.

Baseline demographic and disease characteristics were similar and not statistically different between treatment groups (Table 2). The average wound surface area was $10.0 \mathrm{~cm}^{2}$. The majority of wounds in the CCO group were stage 4 PUs (69\%), while the majority of wounds in the hydrogel group were stage 3 PUs (64\%). However, differences across these two groups were not statistically significant $(P=0.082)$.
Overall, $44.4 \%$ of the study wounds were caused by devices such as splints, braces, ill-fitting wheelchair arm rests, or prostheses. The devices were removed upon discovery of the PU. The majority of wounds (in both groups) were located on the coccyx (30.8\% in the CCO group and $21.4 \%$ in the hydrogel group, respectively) and the left leg (15.4\% for patients treated with $\mathrm{CCO}$ and $14.3 \%$ in the hydrogel cohort, respectively). Difference in wound location across both treatment groups was not statistically different $(P=0.516)$.

Changes in granulation tissue formation throughout the study are shown (Figure 1). Prior to initial application (ie, baseline), wounds in the hydrogel treatment group had a

Table 2 Demographics and baseline clinical characteristics by treatment group

\begin{tabular}{|c|c|c|c|c|}
\hline & All patients & $\mathrm{CCO}$ & Hydrogel & $P$-value ${ }^{a}$ \\
\hline & $\mathbf{N}=\mathbf{2 7}$ & $N=13$ & $N=14$ & \\
\hline \multicolumn{5}{|c|}{ Demographic characteristics } \\
\hline Female, $\%$ & 55.6 & 61.5 & 50.0 & 0.547 \\
\hline \multicolumn{5}{|l|}{ Age, years } \\
\hline Mean (SD) [range] & 79.5 (13.5) [44-94] & $80.2(14.5)$ [44-94] & 78.8 (12.9) [54-94] & 0.787 \\
\hline \multicolumn{5}{|l|}{ Clinical characteristics } \\
\hline Pressure ulcer stage, \% & & & & 0.082 \\
\hline 3 & 48.2 & 30.8 & 64.3 & \\
\hline 4 & 51.8 & 69.2 & 35.7 & \\
\hline Wound location, \% & & & & 0.516 \\
\hline Coccyx & 25.9 & 30.8 & 21.4 & \\
\hline Sacrum & 7.4 & 7.7 & 7.1 & \\
\hline Scapula & 3.7 & 0.0 & 7.1 & \\
\hline Scalp & 3.7 & 7.7 & 0.0 & \\
\hline Left leg & 14.8 & 15.4 & 14.3 & \\
\hline Left knee & 7.4 & 15.4 & 0.0 & \\
\hline Left arm & 3.7 & 0.0 & 7.1 & \\
\hline Left chest & 3.7 & 0.0 & 7.1 & \\
\hline Left hip & 3.7 & 0.0 & 7.1 & \\
\hline Right leg & 3.7 & 0.0 & 7.1 & \\
\hline Right knee & 3.7 & 0.0 & 7.1 & \\
\hline Right hip & 3.7 & 7.7 & 0.0 & \\
\hline Right elbow & 3.7 & 7.7 & 0.0 & \\
\hline Right heel & 3.7 & 0.0 & 7.1 & \\
\hline Right posterior thigh & 3.7 & 0.0 & 7.1 & \\
\hline RLQ abdomen & 3.7 & 7.7 & 0.0 & \\
\hline Device-related ulcers, \% & 44.4 & 38.5 & 50.0 & 0.547 \\
\hline \multicolumn{5}{|l|}{ Age of wound, weeks } \\
\hline Mean (SD) [range] & $3.4(2.7)[1-12]$ & $3.7(3.4)[1-12]$ & $3.0(1.9)[1-7]$ & 0.471 \\
\hline \multicolumn{5}{|l|}{ Prealbumin level } \\
\hline Mean (SD) [range] & 16.7 (I.I) [16-20] & $16.8(1.3)[16-20]$ & $16.6(0.8)[16-18]$ & 0.629 \\
\hline \multicolumn{5}{|l|}{ Wound surface area, $\mathrm{cm}^{2}$} \\
\hline Mean (SD) [range] & $10.0(16.4)[2-57]$ & 12.3 (19.3) [2-57] & 7.9 (13.5) [2-54] & 0.499 \\
\hline \multicolumn{5}{|l|}{ PUSH score } \\
\hline Mean (SD) [range] & II.4 (2.5) [8-16] & II.2(2.6) [8-15] & $11.7(2.4)[9-16]$ & 0.566 \\
\hline \multicolumn{5}{|l|}{ WBS } \\
\hline Mean (SD) [range] & $9.4(1.8)[4-13]$ & $8.9(1.7)[7-13]$ & $9.8(1.9)[4-12]$ & 0.226 \\
\hline \multicolumn{5}{|l|}{ Viable wound bed, $\%$} \\
\hline Mean (SD) [range] & $9.6(7.7)[0-30]$ & $8.8(8.6)[0-30]$ & $10.3(7.1)[0-20]$ & 0.626 \\
\hline
\end{tabular}

Note: ${ }^{a}$ Differences in characteristics between treatment groups were analyzed with one-way analysis of variance for continuous covariates and chi-square analysis for dichotomous variables.

Abbreviations: CCO, clostridial collagenase ointment; SD, standard deviation; RLQ, right lower quadrant; PUSH, Pressure Ulcer Scale for Healing; WBS, wound bed score. 


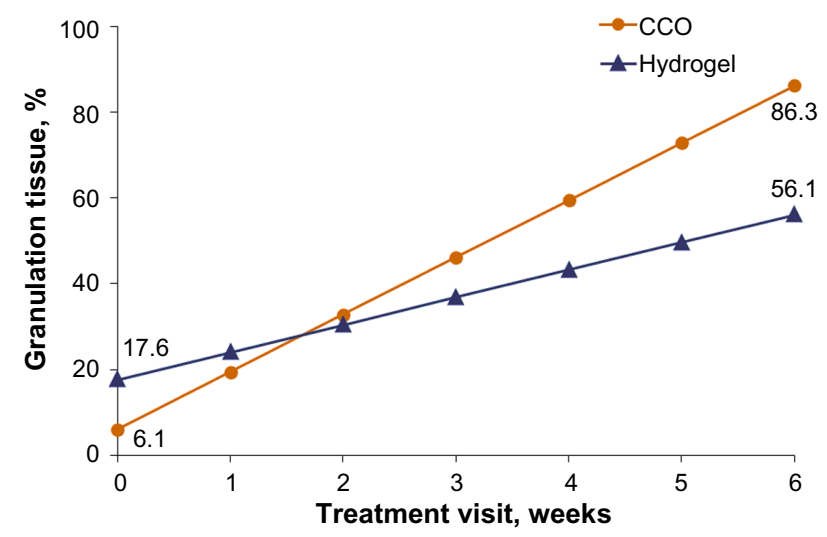

Figure I Regression values of granulation tissue in wound bed, by visit. Abbreviation: $\mathrm{CCO}$, clostridial collagenase ointment.

greater, but not statistically higher, percentage of granulation tissue than those in the CCO treatment group (18\% versus $7 \%$ of wound bed tissue, respectively). Beginning at week 2 , the percentage of healthy granulation tissue in the wounds treated with $\mathrm{CCO}$ was comparable with that of the hydrogel group. After 6 weeks, wounds treated with CCO had a significantly greater percentage of granulation tissue than those treated with hydrogel $(P=0.003)$ Patients receiving $\mathrm{CCO}$ demonstrated an average $2 \%$ gain in granulation tissue per day, compared with $1 \%$ per day for patients receiving hydrogel. Significant predictors of healthy granulation tissue formation were healing time and the interaction of healing time and treatment method $(P<0.0001$ and $P=0.002$, respectively). The effect size was 0.8 , which was indicative of a large clinical benefit (treatment with $\mathrm{CCO}$ was associated with 0.8 of one standard deviation increase in healthy granulation tissue).

Prior to initial application, the mean WBS of wounds in the hydrogel treatment group (10.7) was better than that of the CCO treatment group (9.2; Figure 2); however, this difference

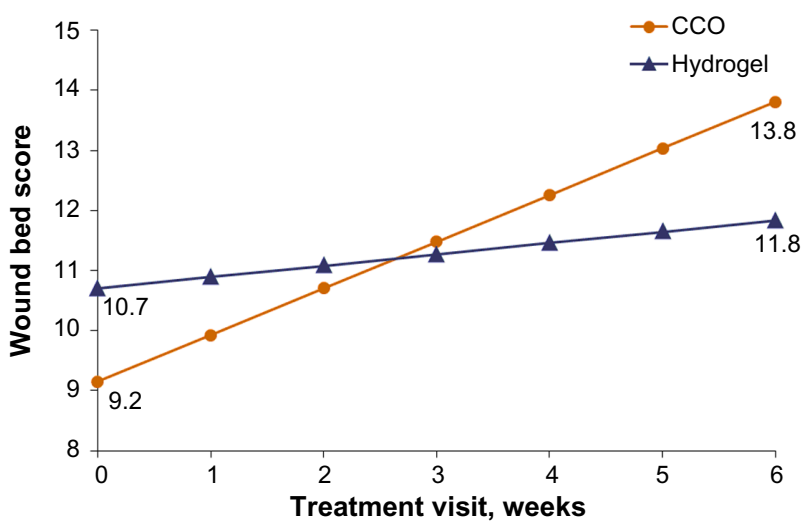

Figure 2 Regression values of wound bed score, by visit. Abbreviation: $\mathrm{CCO}$, clostridial collagenase ointment. was not statistically different $(P=0.226)$. By week 3 , however, wounds treated with $\mathrm{CCO}$ had better mean WBS values than those treated with hydrogel (Figure 2). After 6 weeks of treatment, patients treated with CCO improved by 4.6 WBS units compared with 2.6 units in the hydrogel group. Results from the linear regression model indicated that the WBS values of wounds treated with $\mathrm{CCO}$ improved more rapidly than those treated with hydrogel. Time and the interaction between treatment and time were significant predictors of WBS gains ( $P<0.0001$ and $P=0.001$, respectively). Effect size comparing the two treatment groups was 0.7 , demonstrating that $\mathrm{CCO}$ treatment has a strong effect on WBS.

Baseline wound surface area was larger, but not significantly higher $(P=0.499)$, in the CCO group than in the hydrogel group $\left(10.3 \mathrm{~cm}^{2}\right.$ and $6.5 \mathrm{~cm}^{2}$, respectively; Figure 3). After 6 weeks of hydrogel treatment, there was a trend toward reduced wound size (from $6.5 \mathrm{~cm}^{2}$ at baseline to $3.0 \mathrm{~cm}^{2}$ at week 6 ), although this reduction was not statistically significant. In contrast, wounds treated with $\mathrm{CCO}$ were significantly smaller after treatment (from $10.3 \mathrm{~cm}^{2}$ at baseline to $2.1 \mathrm{~cm}^{2}$ at week $6 ; P=0.009$ ). Linear regression analysis showed no significant predictors of wound surface area reduction. Given that the change in wound surface area from baseline to week 6 for the hydrogel group was not significant, effect size was only examined within the $\mathrm{CCO}$ group. From baseline to follow-up, the effect size for $\mathrm{CCO}$ was 0.6 , which indicates a moderate impact of change in wound surface area.

Closure rates, as measured by percentage of epithelialized cells in the wound, were numerically higher in wounds treated with CCO (31\%) than in those treated with hydrogel (14\%), although this difference was not statistically significant (Figure 4). Wound closure began earlier in wounds treated with hydrogel than in those treated with $\mathrm{CCO}$.

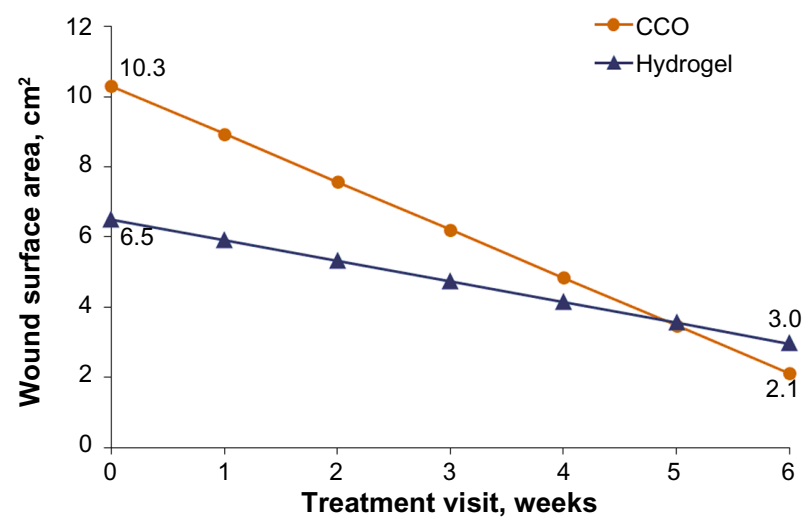

Figure 3 Regression values of wound surface area, by visit. Abbreviation: $\mathrm{CCO}$, clostridial collagenase ointment. 


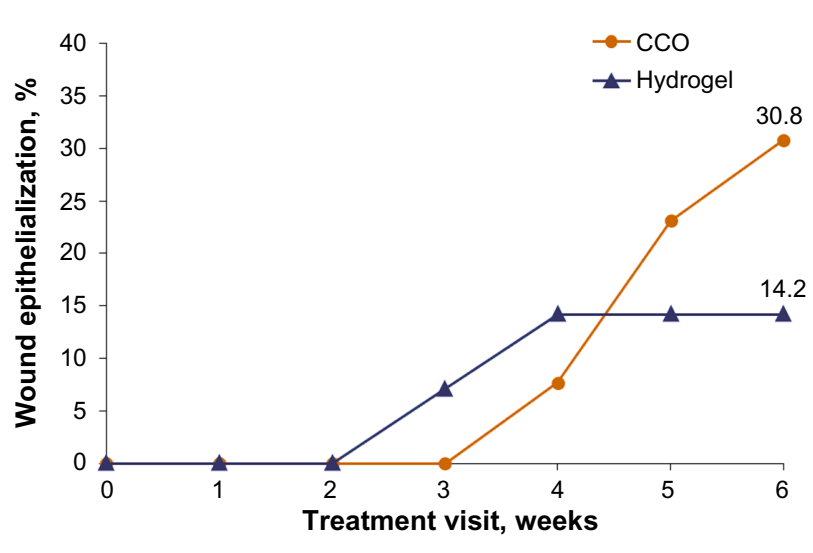

Figure 4 Wound epithelialization, by treatment visit. Abbreviation: $\mathrm{CCO}$, clostridial collagenase ointment.

\section{Discussion}

PU treatment remains a major therapeutic challenge. There is a pressing need for clinically effective treatments that reduce the burden of care and increase patient quality of life. To promote healing, a healthy ulcer environment must be created by removing barriers to healing and maintaining an appropriate moisture balance. This blinded, randomized, controlled trial compared two methods of wound debridement: enzymatic debridement with $\mathrm{CCO}$ and autolytic debridement with a hydrogel. In this study, wounds treated with $\mathrm{CCO}$ had significantly faster rates of healthy granulation tissue formation, greater WBS gains, and more rapid improvements in wound surface area.

Debridement of chronic wounds aims to clear away impediments to healing rapidly and effectively. ${ }^{11}$ The choice of debridement methods depends on the clinician and the care setting. Suitable methods might include serial sharp debridement or alternative methods such as enzymatic or autolytic debridement.

Autolytic debridement using a hydrogel facilitates liquefaction of nonviable tissues; it is frequently used after surgical removal of necrotic tissue to provide moisture to the wound bed. General comparisons between this class of topical wound treatment and other, nonhydrogel treatments are difficult due to the large variety of hydrophilic components and water content of hydrogels. Overall, hydrogels have demonstrated superiority to moist saline gauze dressings, ${ }^{41}$ replacing wet-to-dry dressings as the active comparator. ${ }^{41-44}$ Evidence-based practice has supported this method to achieve initial debridement in certain clinical situations. ${ }^{45}$ Studies with multiple hydrogels have found that no particular hydrogel offered clinical benefit over another. ${ }^{44,46}$

In a long-term care facility, enzymatic debridement using $\mathrm{CCO}$ is an efficient alternative treatment approach for the treatment of PUs. Several studies have demonstrated that enzymatic debridement using $\mathrm{CCO}$ is both clinically effective and well tolerated..$^{10,15,33,47-50}$ Using a decision analytic module, Mosher et $\mathrm{al}^{17}$ compared enzymatic debridement using $\mathrm{CCO}$ with autolytic debridement using a hydrogel. The probability of achieving complete debridement of nonviable tissue in new full-thickness PUs within 2 weeks was $70 \%$ for CCO versus $50 \%$ with hydrogel. ${ }^{17}$ In an extension study, the outcomes of these patients were assessed 3 months later; wounds treated with CCO had significantly higher closure rates than those treated with hydrogel. ${ }^{33}$ These results are consistent with the current findings. Notably, statistically significant improvement in WBS was achieved, although the wounds were not cross-hatched, which strengthens the applicability of these techniques to long-term care settings.

Per the inclusion/exclusion criteria of this study, patients had to have an ulcer size between $1 \mathrm{~cm}^{2}$ and $64 \mathrm{~cm}^{2}$ and receive adequate pressure redistribution to the affected area via devices such as a specialty bed, a wheelchair cushion, and/or an offloading device. The overall device-related PUs in this study was approximately $44.4 \%$. This was the first study to report device-related PUs in a long-term care setting. While this number is slightly higher relative to the overall PU population, acute care-related studies have reported device-related PU prevalence rates up to $34 \% .{ }^{51,52}$ They are often linked with endotracheal tubes, tracheostomy tubes, and oxygen masks/ delivery systems. ${ }^{53-55}$ Furthermore, continence management devices such as urinary catheters and fecal containment devices are often implicated. ${ }^{51,53,54,56,57}$ It has been suggested that the prevalence of these ulcers may be underestimated because systematic evaluation for device-related PU recurrence is not part of a routine skin assessment. ${ }^{58}$ While PUs cause pain and suffering, impair quality of life, are expensive to treat, and require lengthy healing time, limited attention has been given to device-related PUs. Further work is needed to compare differences in long-term care and acute care populations to document the extent of the problem of device-related PUs, determine population differences (if any), and evaluate the most effective treatment options specific to each setting.

In support of previous findings, WBS outcomes reported here support the ability of the WBS to predict complete wound closure. ${ }^{39}$ Higher scores of the WBS favor wound closure in PUs. Such quantitative measurement tools can provide reliable objectivity to the clinician in guiding treatment decisions until more advanced diagnostic testing, such as biological markers that correlate with wound health, is developed and becomes available.

Certain limitations should be considered when interpreting these results. First, results cannot be generalized to 
wounds of other etiologies (ie, diabetic foot ulcers, venous leg ulcers, or other chronic wounds). They also cannot be extended to patients in other age groups or those treated in other care settings (ie, ambulatory, outpatient, or inpatient). In addition, results cannot be generalized to other autolytic dressings. Device-related PUs were not analyzed separately; however, given the low number of enrolled patients, analyzing these wounds separately would have resulted in a loss of statistical power. Pain was not assessed, due to the difficulty of obtaining reliable responses for cognitively impaired patients in a long-term care environment. Furthermore, comorbidity information was collected; however, given that the populations were similar across most conditions, statistical analyses were not performed. This study is limited by the low number of enrolled patients, although the statistical differences between the two debridement groups suggest that higher enrollment numbers may not produce markedly different results. Future studies that compare differences in granulation tissue formation, wound surface area reduction, WBS scores, and epithelialization rates across PUs and device-related PUs in long-term care settings are warranted. Health care providers should identify differences (if any) across these two types of PUs and identify proper treatment algorithms for each to achieve the most effective method of wound bed healing.

Optimizing PU treatment is a continuing challenge for long-term care providers. In the current 6-week study, wounds treated with enzymatic debridement using CCO had more rapid granulation tissue formation, WBS improvement, wound size reduction, and improved closure rates than wounds treated with autolytic debridement using a hydrogel. Health care providers should consider enzymatic debridement along with a validated predictive wound healing tool to potentially improve clinical outcomes in patients with PUs in a long-term care setting.

\section{Acknowledgment}

Medical writing assistance was provided by Kathryn Clausen of JK Medical Communications, Inc., Conshohocken, PA, USA. This assistance was funded by Smith and Nephew.

\section{Disclosure}

Curtis R Waycaster and Adrienne M Gilligan are employees of Smith and Nephew Inc. Catherine T Milne has no financial disclosures.

\section{References}

1. Lyder CH. Pressure ulcer prevention and management. JAMA. 2003;289: 223-226.
2. Gordon MD, Gottschlich MM, Helvig EI, et al. Review of evidencebased practice for the prevention of pressure sores in burn patients. J Burn Care Rehabil. 2004;25:388-410.

3. Kuhn BA. Balancing the pressure ulcer cost and quality equation. Nurs Econ. 1992;10:353-359.

4. Graves N, Birrell F, Whitby M. Effect of pressure ulcers on length of hospital stay. Infect Control Hosp Epidemiol. 2005;26:293-297.

5. Berlowitz DR, Brandeis GH, Anderson J, Du W, Brand H. Effect of pressure ulcers on the survival of long-term care residents. $J$ Gerontol A Biol Sci Med Sci. 1997;52:M106-M110.

6. Thomas DR, Goode PS, Tarquine PH, Allman RM. Hospital-acquired pressure ulcers and risk of death. J Am Geriatr Soc. 1996;44: 1435-1440.

7. Schultz GS, Sibbald RG, Falanga V, et al. Wound bed preparation: a systematic approach to wound management. Wound Repair Regen. 2003;11:1-28.

8. Phillips TJ, Ouahes N. Leg ulcers. Curr Probl Dermatol. 1995;7(4): 109-142.

9. Falanga V. Classifications for wound bed preparation and stimulation of chronic wounds. Wound Repair Regen. 2000;8:347-352.

10. Brem H, Balledux J, Sukkarieh T, Carson P, Falanga V. Healing of venous ulcers of long duration with a bilayered living skin substitute: results from a general surgery and dermatology department. Dermatol Surg. 2001;27:915-919.

11. Steed DL. Debridement. Am J of Surg. 2004;187:71S-74S.

12. Ramundo J, Gray M. Collagenase for enzymatic debridement: a systematic review. J Wound Ostomy Continence Nurs. 2009;36(Suppl 6):S4-S11.

13. Carter MJ. Cost-effectiveness research in wound care: definitions, approaches, and limitations. Ostomy Wound Manage. 2010;56(11): 48-59.

14. Moore J, Jensen P. Assessing the role and impact of enzymatic debridement. Podiatry Today. 2004;17(7):54-61.

15. Milne CT, Ciccarelli AO, Lassy M. A comparison of collagenase to hydrogel dressings in wound debridement. Wounds. 2010;22(11):270-274.

16. Moore J, Jensen P. Assessing the role and impact of enzymatic debridement. Podiatry Today. 2004;17(7):54-61.

17. Mosher BA, Cuddigan J, Thomas DR, Boudreau DM. Outcomes of 4 methods of debridement using a decision analysis methodology. $A d v$ Wound Care. 1999;12(2):81-88.

18. Thomas S, Jones H. Clinical experiences with a new hydrogel dressing. $J$ Wound Care. 1996;5(3):132-133.

19. Ayello EA, Cuddigan J, Kerstein MD. Skip the knife: debriding wounds without surgery. Nursing. 2002;32(9):58-64.

20. Mulder GD. Cost-effective managed care: gel versus wet-to-dry for debridement. Ostomy Wound Manage. 1995;41(2):68-74.

21. Ayello E, Cuddigan J. Debridement: controlling the necrotic/cellular burden. Adv Skin Wound Care. 2004;17:66-75.

22. Armstrong DG, Mossel J, Short B, Nixon BP, Knowles EA, Boulton AJ. Maggot debridement therapy: a primer. $J$ Am Podiatr Med Assoc. 2002;92:398-401.

23. Mumcuoglu KY. Clinical applications for maggots in wound care. AmJ Clin Dermatol. 2001;2:219-227.

24. Sherman RA. Maggot therapy for foot and leg wounds. Int J Low Extrem Wounds. 2002;1:135-142.

25. Sherman RA. Maggot therapy for treating diabetic foot ulcers unresponsive to conventional therapy. Diabetes Care. 2003;26:446-451.

26. Parnes A, Lagan KM. Larval therapy in wound management: a review. Int J Clin Prac. 2007;61(3):488-493.

27. Vowden K, Vowden P. Wound bed preparation. World Wide Wounds. 2002. Available from: http://www.worldwidewounds.com/2002/april/ Vowden/Wound-Bed-Preparation.html. Accessed September 26, 2014.

28. Vowden KR, Vowden P. Wound debridement, part 2: sharp techniques. J Wound Care. 1999;8(6):291-294.

29. TurnerT. The development of wound management products. In: Krasner DL, Rodeheaver GT, Sibbald RG, editors. Chronic Wound Care: A Clinical Source Book for Healthcare Professionals. 3rd ed. Wayne, PA: HMP Communications; 2001. 
30. Strohal R, Dissemond J, O'Brien JJ, et al. EWMA document: debridement an update overview and clarification of the principle role of debridement. J Wound Care. 2013;22(1):S1-S52.

31. Smith RG. Enzymatic debriding agents: an evaluation of the medical literature. Ostomy Wound Manage. 2008;54(8):16-34.

32. McCallon S. Enzymes for wound debridement and healing. ECPN. 2007;120(6):30-35.

33. Milne CT, Ciccarelli AO, Lassy M. A comparison of collagenase to hydrogel dressings in maintenance debridement and wound closure. Wounds. 2012;24(11):317-322.

34. National Pressure Ulcer Advisory Panel and European Pressure Ulcer Advisory Panel. International Guideline: Pressure Ulcer Treatment Technical Report. 2009. Available from: http://www.npuap.org/wpcontent/uploads/2012/03/Final-2009-Treatment-Technical-Report1. pdf. Accessed September 26, 2014.

35. Collagenase Santyl [package insert]. Fort Worth, TX: Smith and Nephew Biotherapeutics; 2013.

36. Rogers LC, Bevilacqua NJ, Armstrong DG, Andros G. Digital planimetry results in more accurate wound measurements: a comparison to standard ruler measurements. J Diabetes Sci Technol. 2010;4(4): 799-802.

37. PictZar.com [homepage on the Internet]. PictZar Digital Planimetry Software. 2011. Available from: http://www.pictzar.com. Accessed September 26, 2014.

38. National Pressure Ulcer Advisory Panel (NPUAP). PUSH Tool 3.0. Available from: http://www.npuap.org/PDF/push3.pdf. Accessed September 26, 2014.

39. Falanga V, Saap LJ, Ozonoff A. Wound bed score and its correlation with healing of chronic wounds. Dermatol Ther. 2006;19(6):383-390.

40. Tukey JW. Exploratory Data Analysis. Reading, MA: Addison-Wesley; 1977.

41. Edwards J, Stapley S. Debridement of diabetic foot ulcers. Cochrane Database Syst Rev. 2010;1:CD003556.

42. Morin RJ, Tomaselli NL. Interactive dressings and topical agents. Clin Plast Surg. 2007;34(4):643-658.

43. Sussman C, Bates-Jensen B. Wound Care: A Collaborative Practice Manual for Health Professionals. 4th ed. Philadelphia, PA: Lippincott, Williams and Wilkins; 2011.

44. Eisenbud D, Hunter H, Kessler L, Zulkowski K. Hydrogel wound dressings: where do we stand in 2003? Ostomy Wound Manage. 2003;49(10):52-57.
45. Panuncialman J, Falanga V. The science of wound bed preparation. Clin Plast Surg. 2007;34(4):621-632.

46. Bale S, Banks V, Haglestein S, Harding KG. A comparison of two amorphous hydrogels in the debridement of pressure sores. $J$ Wound Care. 1998;7(2):65-68.

47. Shi L, Carson D. Collagenase Santyl ointment: a selective agent for wound debridement. J Wound Ostomy Continence Nurs. 2009; 36(Suppl 6):S12-S16

48. Shi L, Ramsay S, Ermis R, Carson D. pH in the bacteria-contaminated wound and its impact on clostridium histolyticum collagenase activity: implications for the use of collagenase wound debridement agents. $J$ Wound Ostomy Continence Nurs. 2011;38:514-521.

49. Ostlie DJ, Juang D, Aguayo P, et al. Topical silver sulfadiazine vs collagenase ointment for the treatment of partial thickness burns in children: a prospective randomized trial. J Pediatr Surg. 2012;47: 1204-1207.

50. Palmieri B, Magri M. A new formulation of collagenase ointment (Iruxol ${ }^{\circledR}$ mono) in the treatment of ulcers of the lower extremities: a randomised, placebo-controlled, double- blind study. Clin Drug Investig. 1998;15:381-387.

51. VanGilder C, Amlung S, Harrison P, Meyer S. Results of the 2008-2009 international pressure ulcer prevalence survey and a 3-year, acute care, unit-specific analysis. Ostomy Wound Manage. 2009;55(11):39-45.

52. Chendrasekhar A, Moorman DW, Timberlake GA. An evaluation of the effects of semi-rigid cervical collars in patients with severe closed head injury. Am Surg. 1998;64:604-606.

53. Boesch RP, Myers C, Garrett T, et al. Prevention of tracheostomyrelated pressure ulcers in children. Pediatrics. 2012;129:e792-e797.

54. Apold J, Rydrych D. Preventing device-related pressure ulcers: using data to guide statewide change. J Nurs Care Qual. 2012;27:28-34.

55. Watts D, Abrahams E, MacMillan C, et al. Insult after injury: pressure ulcers in trauma patients. Orthop Nurs. 1998;17:84-91.

56. Black JM, Cuddigan JE, Walko ME, Didier LA, Lander MJ, Kelpe MR. Medical device related pressure ulcers in hospitalised patients. Int Wound J. 2010;7:358-365.

57. Chendrasekhar A, Moorman DW, Timberlake GA. An evaluation of the effects of semi-rigid cervical collars in patients with severe closed head injury. Am Surg. 1998;64:604-606.

58. Coyer FM, Stotts NA, Blackman VS. A prospective window into medical device-related pressure ulcers in intensive care. Int Wound J. $2013 ; 1-9$.
Chronic Wound Care Management and Research

\section{Publish your work in this journal}

Chronic Wound Care Management and Research is an international, peer reviewed, open access, online journal publishing original research, reviews, editorials, and commentaries on the causes and management of chronic wounds and the major issues related to chronic wound management. Topics also include chronic wounds as comorbidities to other

\section{Dovepress}

conditions, patient adherence to therapy, and the economic burden of chronic wounds. The manuscript management system is completely online and includes a very quick and fair peer review system, which is all easy to use. Visit http://www.dovepress.com/testimonials.php to read real quotes from published authors. 